\title{
Genome-Informed Recombinase Polymerase Amplification Assay Coupled with a Lateral Flow Device for In-Field Detection of Dickeya Species
}

\author{
Gamze Boluk, ${ }^{1}$ Shefali Dobhal, ${ }^{1}$ Alex B. Crockford, ${ }^{2}$ Michael Melzer, ${ }^{1}$ Anne M. Alvarez, ${ }^{1}$ and Mohammad Arif ${ }^{1, \dagger}$ \\ ${ }^{1}$ Department of Plant and Environmental Protection Sciences, University of Hawaii at Manoa, Honolulu, HI 96822, U.S.A. \\ ${ }^{2}$ Wisconsin Seed Potato Certification Laboratory, University of Wisconsin-Madison, Madison, WI 53706, U.S.A.
}

\begin{abstract}
Dickeya spp. cause blackleg and soft rot diseases of potato and several other plant species worldwide, resulting in high economic losses. Rapid detection and identification of the pathogen is essential for facilitating efficient disease management. Our aim in this research was to develop a rapid and field-deployable recombinase polymerase amplification (RPA) assay coupled with a lateral flow device (LFD) that will accurately detect Dickeya spp. in infected plant tissues without the need for DNA isolation. A unique genomic region $(\mathrm{mglA} / \mathrm{mglC}$ genes) conserved among Dickeya spp. was used to design highly specific robust primers and probes for an RPA assay. Assay specificity was validated with 34 representative strains from all Dickeya spp. and 24 strains from other genera and species; no false positives or negatives were detected. An RPA assay targeting the internal

transcribed spacer region of the host genome was included to enhance the reliability and accuracy of the Dickeya assay. The detection limit of $1 \mathrm{fg}$ was determined by both sensitivity and spiked sensitivity assays; no inhibitory effects were observed when $1 \mu l$ of host sap, macerated in Tris-EDTA buffer, was added to each reaction in the sensitivity tests. The developed RPA assay is rapid, highly accurate, sensitive, and fully field deployable. It has numerous applications in routine diagnostics, surveillance, biosecurity, and disease management.

Keywords: bacteria, blackleg and soft rot diseases, diagnostics, Dickeya spp., field deployable, recombinase polymerase amplification (RPA), RPA diagnostics, techniques
\end{abstract}

Dickeya spp. are Gram-negative, fermentative, and motile plantpathogenic bacteria that produce extracellular pectinolytic enzymes which are imperative for the phytopathological process. Other key factors such as oxygen availability, temperature, and humidity also play a significant role in pathogenesis of Dickeya spp. (Perombelon 2002). Previously included in a diverse group of phytopathogens called Erwinia chrysanthemi, these soft-rotting and vascular phytopathogens were reclassified into six species of Dickeya (Samson et al. 2005) and now the genus includes eight species; namely, Dickeya aquatica, D. chrysanthemi, D. dadantii, D. dianthicola, D. fangzhongdai, D. paradisiaca, D. solani, and D. zeae (Brady et al. 2012; Parkinson et al. 2014; Tian et al. 2016; van der Wolf et al. 2014).

Dickeya spp. cause disease on a wide range of host plants, including potato (Solanum tuberosum L.) (Samson et al. 2005), which is a multibillion-dollar industry in the United States, valued at $\$ 3.7$ billion in 2018 by the National Potato Council. On potato, symptoms include blackleg, soft rot, and stem rot (Laurila et al. 2009; Ngadze et al. 2010; Pérombelon 2002). In addition, wilting of leaves followed by discoloration of the vascular system are common symptoms. Dickeya spp. are widespread because potato plants are grown across Eastern and Northern Europe, Israel, and other parts of the world (Boluk and Arif 2019; Golanowska et al. 2016; Joutsjoki et al. 2005; Laurila et al. 2009; Palacio-Bielsa et al. 2006; Tsror et al. 2008). Apart from potato, other hosts include banana, tomato,

${ }^{\dagger}$ Corresponding author: M. Arif; arif@hawaii.edu

Funding: This work was supported by the United States Department of Agriculture National Institute of Food and Agriculture, Hatch project 9038H, managed by the College of Tropical Agriculture and Human Resources. The strains used in this study were revived and further characterized with grant support from the National Science Foundation (NSF-CSBR grant number DBI-1561663).

The author(s) declare no conflict of interest.

Accepted for publication 18 February 2020.

(C) 2020 The American Phytopathological Society sugar beet, pineapple, onion, pear, maize, rice, and a variety of ornamental plants (Gardan et al. 2003; Ma et al. 2007; Palacio-Bielsa et al. 2006; Samson et al. 2005; Sueno et al. 2014; Tian et al. 2016). Pineapple heart rot, previously attributed to E. chrysanthemi (Kaneshiro et al. 2008), and stalk rot of corn differ somewhat in symptom expression but both diseases are now attributed to D. zeae (Kumar et al. 2017; Marrero et al. 2013; Sueno et al. 2014). Symptoms on pear include bleeding canker of tree trunks, which is caused by the recently defined species $D$. fangzhongdai (Tian et al. 2016).

In order to detect and identify Dickeya spp., several traditional diagnostic methods are used, including semiselective crystal-violet pectate medium, biochemical tests, and enzyme-linked immunosorbent assay (Samson et al. 2005; Singh et al. 2000), but these methods are often time consuming and laborious, or require a skilled technician. PCR and quantitative PCR (qPCR)-based methods are more sensitive; numerous methods have already been published for different Dickeya spp. However, these techniques require facilities that are adequately equipped to run such diagnostic tests (Czajkowski et al. 2015; Hommais et al. 2011; Humphris et al. 2015; Nassar et al. 1996; Pritchard et al. 2013, 2016). Dickeya spp. were characterized using multilocus sequence typing, amplified fragment length polymorphism, DNA-DNA hybridization (Avrova et al. 2002; Brady et al. 2012; Fujimoto et al. 2018; Marrero et al. 2013; Nassar et al. 1996; Slawiak et al. 2009; van der Wolf et al. 2014; Waleron et al. 2002), and other PCR-based methods, including end-point PCR, multiplex PCR, and real-time qPCR (Czajkowski et al. 2015; Dobhal et al. 2020). Among these methods, real-time qPCR has shown high sensitivity but cannot be performed in field.

The field-deployable, loop-mediated isothermal amplification (LAMP) method is rapid and eliminates the requirement of expensive and sophisticated thermocycler (Dobhal et al. 2019; LarreaSarmiento et al. 2018; Notomi et al. 2000; Ocenar et al. 2019; Yasuhara-Bell et al. 2017). However, LAMP still relies on purified DNA and that is a challenging task to perform in field settings.

Recombinase polymerase amplification (RPA) is a comparatively new isothermal technique, which works at 37 to $42^{\circ} \mathrm{C}$ without the need of purified genomic DNA (Ahmed et al. 2018; Arif et al. 2016; Piepenburg et al. 2006). RPA now is being used to detect a multitude of pathogens that infect humans, animals, and plants. The RPA lateral 
flow device (LFD) assay is rapid and can be done within 45 min from sample processing to detection (Ahmed et al. 2018). The amplified RPA product can be visualized on an LFD labeled with fluorescein isothiocyanate and biotin. This visual detection requires the modified oligonucleotides and probe used to amplify the target region.

The objective of this study was to develop a rapid RPA assay coupled with an LFD for specific and robust detection of Dickeya spp. in field settings without the need for purified DNA. The developed assay has tremendous applications in routine diagnostics, biosecurity, epidemiology, and disease management, and to effectively combat new disease outbreaks.

\section{Materials and Methods}

Source of bacterial strains and DNA extraction. In total, 58 strains were studied, including 34 strains of Dickeya spp. (Table 1) and 24 strains (Table 2) from closely related genera or species or other microorganisms found in the niche. These bacterial cultures were obtained from different hosts and geographical regions around the world. The strains were stored at $-80^{\circ} \mathrm{C}$ and regrown on TZC (tetrazolium chloride) medium (Dobhal et al. 2020; Larrea-Sarmiento et al. 2018). Plates were incubated at $26 \pm 2{ }^{\circ} \mathrm{C}$. A single colony was picked and multiplied to eliminate any possibility of contamination. The UltraClean Microbial DNA Isolation Kit (MO BIO, Carlsbad, CA, U.S.A.) was used to extract the genomic DNA from all pure strains. The concentration of extracted DNA was measured using a NanoDrop 2000 (Thermo Fisher Scientific Inc, Worcester, MA, U.S.A.); extracted DNA was stored in a freezer at $-20^{\circ} \mathrm{C}$. The identity of each strain was confirmed by amplifying either dnaA (chromosomal replication initiator protein) or $16 \mathrm{~S}$ ribosomal RNA partial gene region (Dobhal et al. 2020).
RPA primers and probe design. The genomes of $D$. dianthicola (NZ_CP017638 and NZ_CM001840), D. solani (NZ_CP015137 and NZ_CP009460), D. zeae (NC_013592 and NZ_CP006929), D. dadantii (NZ_CP002038), D. chrysanthemi (NZ_CM001904), D. fangzhongdai (NZ_CP025003), and D. paradisiaca (NZ_CM001857) were retrieved from the NCBI GenBank genome database. The whole genomes were aligned using progressiveMauve plugged into Geneious 10.2.3 (Biomatters, Auckland, NZ), and used to evaluate primers and probe's in silico specificity (Dobhal et al. 2020). The $m g l \mathrm{~A} / \mathrm{mglC}$ genomic region was used to design specific RPA primers and a probe to detect all Dickeya spp. (Dobhal et al. 2020). The RPA sense and antisense primers and probe were designed manually (Table 3 ). The reverse primer DIC-RPAR1 was labeled with biotin at the $5^{\prime}$ position and the probe was labeled with 6-carboxy-fluorescein (FAM) (Fig. 1). The RPA assay, designed using the host internal transcribed spacer (ITS) region, was also included in the validation (Ahmed et al. 2018) (Table 3).

The RPA reaction and analysis. The RPA reaction was performed using the TwistAmp Exo kit (TwistDX Limited, Maidenhead, U.K.) following the manufacturer's instructions. Briefly, RPA reactions were carried out in a total of $50 \mu \mathrm{l}$ of reaction volume containing $29.5 \mu \mathrm{l}$ of rehydration buffer, $0.6 \mu \mathrm{l}(10 \mu \mathrm{M})$ of probe, $2.1 \mu \mathrm{l}(10 \mu \mathrm{M})$ of each forward and reverse primer, $12.5 \mu \mathrm{l}$ of nuclease-free water, $1 \mu \mathrm{l}$ of DNA template or macerated plant sap (Ahmed et al. 2018), and $2.5 \mu \mathrm{l}$ of magnesium acetate to activate the reaction. The reaction mixture was incubated at a fixed temperature of $42^{\circ} \mathrm{C}$ for $30 \mathrm{~min}$. Each RPA run was performed with a positive control (target DNA) and a nontemplate control (nuclease-free water). After completion of the amplification reaction, $5 \mu \mathrm{l}$ of RPA product was added to a mix of $500 \mu l$ of buffer $(250 \mu l$ of

Table 1. Bacterial strains used an inclusivity panel to validate recombinase polymerase amplification (RPA) assay for specific detection of Dickeya spp.

\begin{tabular}{|c|c|c|c|c|c|c|}
\hline Isolate & Original ID & Organism & Location & Host & GenBank $^{\mathbf{a}}$ & $\mathbf{R P A}^{\mathbf{b}}$ \\
\hline A5415 & CFBP2048 & Dickeya chrysanthemi & United States & Chrysanthemum morifolium & MH453538 & + \\
\hline A5641 & CFBP1270 & D. chrysanthemi & Denmark & Parthenium argentatum & MH453539 & + \\
\hline A5576 & PRI2120 & D. dadantii & Comoros & Perlagonium capitatum & MK208948 & + \\
\hline A5642 & CFBP3855 & D. dadantii & France & Saintpaulia sp. & MH453542 & + \\
\hline A5643 & CFBP6467 & D. dadantii & Martinique, France & Musa sp. & MK208950 & + \\
\hline A6060 & CFBP3698 & D. dadantii & Cuba & Musa sp. & MK208956 & + \\
\hline A6061 & CFBP1247 & D. dadantii & United States & Dieffenbachia picta & MK208957 & + \\
\hline A5418 & CFBP1200 & D. dianthicola & United Kingdom & Dianthus caryophyllus & MK208961 & + \\
\hline A5566 & PRI1363 & D. dianthicola & The Netherlands & Solanum tuberosum & MK208962 & + \\
\hline A5567 & PRI1370 & D. dianthicola & The Netherlands & S. tuberosum & MK208963 & + \\
\hline A5569 & PRI1372-B & D. dianthicola & The Netherlands & S. tuberosum & MK208965 & + \\
\hline A5573 & PRI2114 & D. dianthicola & United Kingdom & D. caryophyllus & MK208947 & + \\
\hline A5644 & CFBP2015 & D. dianthicola & France & S. tuberosum & MK208951 & + \\
\hline A5645 & CFBP4155 & D. dianthicola & The Netherlands & Kalanchoe blossfeldiana var. Maes & MK208952 & + \\
\hline A6058 & CFBP1982 & D. dianthicola & France & Dahlia sp. & MK208953 & + \\
\hline A6059 & CFBP3706 & D. dianthicola & Switzerland & Cichorium intybus & MK208955 & + \\
\hline PL22 & GBp1A & D. dianthicola & Hawaii, U.S.A. & S. tuberosum & MK189269 & + \\
\hline PL23 & GBp10B & D. dianthicola & Hawaii, U.S.A. & S. tuberosum & MK189270 & + \\
\hline PL24 & GBp11A & D. dianthicola & Hawaii, U.S.A. & S. tuberosum & MK189271 & + \\
\hline PL25 & GBp21C & D. dianthicola & Hawaii, U.S.A. & S. tuberosum & MK189268 & + \\
\hline A5579 & PRI2127 & D. paradisiaca & Columbia & M. paradisiaca & MK208943 & + \\
\hline A5420 & CFBP4178 & D. paradisiaca & Colombia & M. paradisiaca & MK208942 & + \\
\hline A5581 & PRI2187 & D. solani & Israel & S. tuberosum & MH453540 & + \\
\hline A5582 & PRI2188 & D. solani & Israel & S. tuberosum & MH453541 & + \\
\hline A5422 & CFBP 2052 & D. zeae & United States & Zea mays & MH453537 & + \\
\hline A6069 & CFBP1277 & D. zeae & United States & Z. mays & MK208960 & + \\
\hline A6056 & 3 leaf & D. zeae & Hawaii, U.S.A. & Ananas comosus & MH453535 & + \\
\hline A5269 & $1-6 \mathrm{~A}$ & D. zeae & Hawaii, U.S.A. & A. comosus & MN045867 & + \\
\hline A5265 & $1-3 \mathrm{~A}$ & D. zeae & Hawaii, U.S.A. & A. comosus & MK189273 & + \\
\hline A5423 & CFBP6466 & D. zeae & Martinique, France & A. comosus & MH453536 & + \\
\hline PL47 & F4-3A2 & D. zeae & Hawaii, U.S.A. & Brassica oleracea var. sabellica & MN045868 & + \\
\hline A5577 & PRI2121 & D. zeae & Malaysia & A. comosus & MK208949 & + \\
\hline A6066 & CFBP1889 & D. zeae & Malaysia & A. comosus & MK208958 & + \\
\hline A6067 & CFBP1890 & D. zeae & Malaysia & A. comosus & MK208959 & + \\
\hline
\end{tabular}

\footnotetext{
a GenBank accession number.

b Positive amplification indicated by + symbol.
} 
water $+250 \mu l$ of buffer; Milenia Biotec, Germany). An LFD was vertically inserted into the dilution mix and left for $5 \mathrm{~min}$.

Determination of limit of detection and spiked assays. The genomic DNA of $D$. dianthicola (strain A5418) was 10-fold serially diluted from $1 \mathrm{ng}$ to $1 \mathrm{fg}$ to determine the detection limit. One microliter from each dilution was used for individual reactions. Two spiked assays were also performed to confirm any inhibitory effect by adding $1 \mu l$ of potato stem or tuber sap to each reaction containing 10-fold serially diluted genomic DNA. A nontemplate control was included in each assay to confirm the reliability of the assay.

Validation of RPA assay with naturally infected plant samples. Eight naturally infected potato plants that showed wilt and soft rot symptoms in the field (P1, P3, P4, P7, P8, P10, P21, and P22) were brought to the laboratory. The samples were disinfected using $0.6 \%$ sodium hypochlorite; plant tissue $\left(1 \mathrm{~cm}^{2}\right)$ was crushed in an Eppendorf tube using a small sterile pestle. A plant tissue kit (Wizard Genomic DNA Purification Kit; Promega Corp., Madison, WI, U.S.A.) was used to extract the genomic DNA following the manufacturer's protocol. Additionally, $50 \mathrm{mg}$ of infected tissues were macerated for $1 \mathrm{~min}$ in $400 \mu \mathrm{l}$ of Tris-EDTA (TE) (1x) buffer using a pestle. The macerated tissues were left for $10 \mathrm{~min}$ at room temperature to let the plant debris settle; $1 \mu l$ of the supernatant was used directly in the RPA reaction (Ahmed et al. 2018).

Confirmation of infection in potato samples. The genomic DNA of naturally infected potato tubers (P1, P3, P4, P7, P8, P10, P21, and $\mathrm{P} 22$ ) was amplified using the primer set of gene dnaA for Dickeya spp. (Dobhal et al. 2020). The PCR contained $10 \mu l$ of GoTaq Green Master Mix (Promega Corp.), $1 \mu \mathrm{l}(5 \mathrm{mM})$ of each forward and reverse primer, $1 \mu \mathrm{l}$ of template DNA, and $7 \mu \mathrm{l}$ of Ultra-Pure DNase/RNase-Free distilled water (Thermo Fisher Scientific). The Dic-dnaA PCR conditions were as follows: initial denaturation at $94^{\circ} \mathrm{C}$ for $5 \mathrm{~min}$; followed by 35 cycles of denaturation at $94^{\circ} \mathrm{C}$ for $20 \mathrm{~s}$, annealing at $58^{\circ} \mathrm{C}$ for $1 \mathrm{~min}$, and extension at $72^{\circ} \mathrm{C}$ for $1 \mathrm{~min}$; final extension at $72^{\circ} \mathrm{C}$ for $2 \mathrm{~min}$; and held at $12^{\circ} \mathrm{C}$. The PCR was performed in a T100 Thermal cycler (Bio-Rad, Hercules, CA, U.S.A.). Agarose gel (1.5\%) electrophoresis was used to separate PCR amplicons. The amplicons were visualized under UV light in a gel documentation system (Bio-Rad Gel Doc-XR+; Bio-Rad). Amplified PCR products were cleaned by adding $2 \mu$ l of ExoSAPIT (Affymetrix Inc, Santa Clara, CA, U.S.A.) in $5 \mu 1$ of PCR product, and incubated at $37^{\circ} \mathrm{C}$ for $15 \mathrm{~min}$ followed by $80^{\circ} \mathrm{C}$ for another $15 \mathrm{~min}$. Treated templates were sequenced using dnaA-F1 and dnaA-R1 sense and antisense primers. Sanger sequencing was performed at the GENEWIZ facility (Genewiz, La Jolla, CA, U.S.A.). The sequences of the sense and antisense strands of each strain were aligned and manually edited in order to rectify any sequencing error. Manually edited sequences were compared against the NCBI GenBank nucleotide and genome databases using the NCBI BLASTn tool. Geneious 10.2.3 was used for editing and alignment (Dobhal et al. 2020).

Validation of RPA assay with artificially infected plant samples. The potato stem tubers, sweet potato (Ipomoea batatas L. (Lam)) root tubers, and taro (Colocasia esculenta L. (Schott)) corms were surface sterilized by dipping them into a beaker containing $0.6 \%$ sodium hypochlorite for $3 \mathrm{~min}$ followed by three consecutive washes with sterilized water. Tubers were cut into thin slices using sterilized scalpel blades. Cut slices were placed in sterile petri dishes with filter paper containing 1 to $2 \mathrm{ml}$ of sterile water to mimic a moist chamber. The potato, taro, and sweet potato slices were stab inoculated with 2 to 3 colonies of D. zeae (A6056) and D. solani (A5581) using a sterile toothpick. All slices were incubated for $24 \mathrm{~h}$ at $28^{\circ} \mathrm{C}$. Tissues were macerated in TE buffer as described above. One microliter of the supernatant was used for the RPA assay. Two replicates of each infected samples of potato, taro, and sweet potato were tested along with the healthy controls (negative control).

RPA assay for plant control. Potato stem tubers were surface sterilized and cut into thin slices using sterilized scalpel blades. The slices were placed in sterile petri dishes the same as described above for the artificially infected plant process. The potato slices were stab-inoculated with Pectobacterium wasabiae (A1852), $P$. carotovorum subsp. odoriferum (A2686), P. carotovorum subsp. brasiliensis (A6152), and P. carotovorum subsp. carotovorum (A5278) using a sterile toothpick. All slices were incubated for $24 \mathrm{~h}$ at $28^{\circ} \mathrm{C}$. The DNA was extracted using the Wizard Genomic DNA Purification Kit following the manufacturer's protocol.

Table 2. Bacterial strains used in exclusivity panel to recombinase polymerase amplification (RPA) assay for specific detection of Dickeya spp.

\begin{tabular}{|c|c|c|c|c|c|c|}
\hline Isolate & Original ID & Organism & Location $^{\text {a }}$ & Host & GenBank $^{\mathbf{b}}$ & $\mathbf{R P A}^{\mathbf{c}}$ \\
\hline A5150 & & Enterobacter asburiae & Hawaii & Zingiber officinale & MK182852 & - \\
\hline \multirow[t]{2}{*}{ A1084 } & QR-6 & Erwinia amylovora & California & Pyrus sp. & MK182851 & - \\
\hline & & Klebsiella sp. & Hawaii & $\ldots$ & MK182844 & - \\
\hline A3131 & ATCC13048 & Klebsiella aerogenes & South Carolina & $\ldots$ & MK208954 & - \\
\hline A1867 & F2c.papaya & Pantoea sp. & Hawaii & Carica papaya & MK182843 & - \\
\hline A 6222 & DP138 & Pantoea agglomerans & Wisconsin & Zea mays & MH547382 & - \\
\hline A5513 & & P. agglomerans & Hawaii & Ornamental & MK182849 & - \\
\hline A5186 & ATCC29267 & P. cypripedii & California & Cypripedium sp. & MK182846 & - \\
\hline A5348 & $2 \mathrm{~d}$ & Pectobacterium aroidearum & Hawaii & Aglaonema sp. & MK182847 & - \\
\hline A1850 & IPM1260 & P. atrosepticum & Colorado & Solanum tuberosum & MH453513 & - \\
\hline A6163 & Eca31 & P. atrosepticum & Wisconsin & S. tuberosum & NS & - \\
\hline A6165 & Ecb1 & P. betavasculorum & California & Beta vulgaris & MK250993 & - \\
\hline A6149 & WPP5 & P. carotovorum subsp. brasiliensis & Wisconsin & S. tuberosum & MH453522 & - \\
\hline A6152 & WPP165 & P. carotovorum subsp. brasiliensis & Wisconsin & S. tuberosum & MH453521 & - \\
\hline A5278 & $1-\# 21$ & P. carotovorum subsp. carotovorum & Hawaii & Irrigation water & MH453511 & - \\
\hline A5280 & $1-\# 31$ & P. carotovorum subsp. carotovorum & Hawaii & Irrigation water & MH453512 & - \\
\hline A5368 & $5 \mathrm{X}$ & P. carotovorum subsp. carotovorum & Hawaii & Aglaonema sp. & MH453510 & - \\
\hline A5350 & $5 \mathrm{C}$ & P. carotovorum subsp. carotovorum & Hawaii & Aglaonema sp. & MK208940 & - \\
\hline A2686 & E43 & P. carotovorum subsp. odoriferum & Hawaii & Brassica oleracea var. capitata & MH453519 & - \\
\hline A1852 & M784 & P. parmanteri & Colorado & S. tuberosum & MH453534 & - \\
\hline A1701 & B94 & Xanthomonas euvesicatoria & California & S. lycopersicum & MH492152 & - \\
\hline A 3617 & XV145 & $X$. vesicatoria & South America & S. lycopersicum & MH492125 & - \\
\hline A2961 & C58 & Agrobacterium tumefaciens & New York & Prunus avium & NS & - \\
\hline A 3450 & 30 & Ralstonia solanacearum & Trinidad and Tobago & S. lycopersicum & MK243481 & - \\
\hline$\ldots$ & $\ldots$ & Healthy plant & Hawaii & S. tuberosum & $\ldots$ & - \\
\hline
\end{tabular}

\footnotetext{
a States in the United States (except for South America and Trinidad and Tobago).

$\mathrm{b}$ GenBank accession number. NS = Sequencing quality was poor, not submitted to NCBI GenBank database.

${ }^{c}$ Negative amplification indicated by - symbol.
} 
IC-RPAF1 and IC-RPAR1 primers and IC-RPAP1 probe were used to detect host DNA, thereby enhancing the accuracy of the developed assays. The RPA primers and probe were designed to detect the genomic DNA of potato (Ahmed et al. 2018). Healthy potato tissues and samples infected with Pectobacterium spp. were assayed with Dickeya sp.- and host-specific primers and probes. The $D$. dianthicola (PL022) genomic DNA was used as a positive control; water was used as a nontemplate control. The inclusion of a plant control RPA assay is essential when detecting the pathogen from infected plant materials.

\section{Results}

Target unique genomic region, primer design, and in silico validation. The unique and conserved $m g l \mathrm{~A} / \mathrm{mglC}$ genomic region used to design the primers and probe was selected after comparing genomes of Dickeya spp. and other closely related species, including Pectobacterium (Dobhal et al. 2020). The selected gene region was analyzed for specificity using NCBI databases. Manually designed long primers and probes were BLASTn against the NCBI GenBank database for in silico validation. BLASTn report showed high specificity-100\% match with only Dickeya sequences, and no sequence match occurred within any other genera, including Pectobacterium, Pantoea, or Enterobacter.

Specificity validation. The broad-range detection capability of the developed RPA assay was assessed with 34 strains of six different Dickeya spp., including D. chrysanthemi, D. dadantii, D. dianthicola, $D$. paradisiaca, $D$. solani, and D. zeae. In the exclusivity panel, 24 strains from seven other bacterial genera (Agrobacterium tumefaciens, Enterobacter aerogenes, E. asburiae, E. cloacae, Erwinia sp., Erwinia amylovora, Klebsiella sp., P. atrosepticum, P. betavasculorum, $P$. carotovorum subsp. brasiliensis, $P$. carotovorum subsp. carotovorum, $P$. carotovorum subsp. odoriferum, $P$. wasabiae, Ralstonia solanacearum, Xanthomonas euvesicatoria, and $X$. vesicatoria) were included to confirm high specificity. No false positives or false negatives were detected. The positive results were only obtained with Dickeya spp. (Fig. 2A) and no positive amplification was observed with any strains of the exclusivity panel (Fig. 2B). The RPA assay was also negative when tested against the healthy plant DNA. Results appearing after $10 \mathrm{~min}$ were not considered. The primers and probe were able to detect only Dickeya spp., indicating that the

Table 3. List of primers and probes used to develop the recombinase polymerase amplification (RPA) lateral-flow strip assay for Dickeya spp.

\begin{tabular}{|c|c|c|c|c|c|c|}
\hline \multirow[b]{2}{*}{ Primer name } & \multirow[b]{2}{*}{ Sequence $^{\mathbf{a}}$} & \multirow[b]{2}{*}{$\mathbf{L}(\mathbf{n t})^{\mathbf{b}}$} & \multirow[b]{2}{*}{ GC $(\%)$} & \multicolumn{3}{|c|}{ BLASTn ${ }^{c}$} \\
\hline & & & & $\mathrm{QC}(\%)$ & E-value & ID $(\%)$ \\
\hline DIC-RPA-F & 5'-GCATTGTCGAAACCAAGAACACCACGCAGAACGA-3' & 34 & 50.00 & 100 & $6 e-08$ & 100 \\
\hline DIC-RPA-R & 5'-/Biosg/ATGCCGCTGTCTTTCAGCCAGGTGAGCGCACTT-3' & 33 & 57.60 & 100 & $2 \mathrm{e}-07$ & 100 \\
\hline DIC-RPA-LP & $\begin{array}{l}\text { 5'-/FAM/TAGCGTCGTTACACCTTTAATGATGCAAGG/Internal } \\
\text { dSpacer/CTGTTACCATGAAAGCTA/Spacer-3' }\end{array}$ & 49 & 42.86 & 100 & $6 e-05$ & 100 \\
\hline 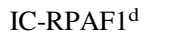 & 5'-AACACAAAC GACTCTCGGCAACGGATATCTCG-3' & 32 & 50.00 & $\ldots$ & $\ldots$ & $\ldots$ \\
\hline IC-RPAR $1^{\mathrm{d}}$ & 5'-/Biosg/ATGGCTTCGGGCGCAACTTGCGTTCAAAGACT-3' & 32 & 53.10 & $\ldots$ & $\ldots$ & $\ldots$ \\
\hline IC-LP & $\begin{array}{l}\text { 5'-/FAM/TGAAGAACGTAGCGAAATGCGATACTTGGT/Internal } \\
\text { dSpacer/TGAATTGCAGAATCCCGTGA/Spacer-3' }\end{array}$ & 50 & 44.00 & $\ldots$ & $\ldots$ & $\ldots$ \\
\hline
\end{tabular}

${ }^{\mathrm{a}} \mathrm{FAM}=6$-carboxy-fluorescein.

${ }^{\mathrm{b}}$ Length in nucleotides (nt).

${ }^{\mathrm{c}} \mathrm{QC}=$ query cover and $\mathrm{ID}=$ percent identity.

d Ahmed et al. (2018).

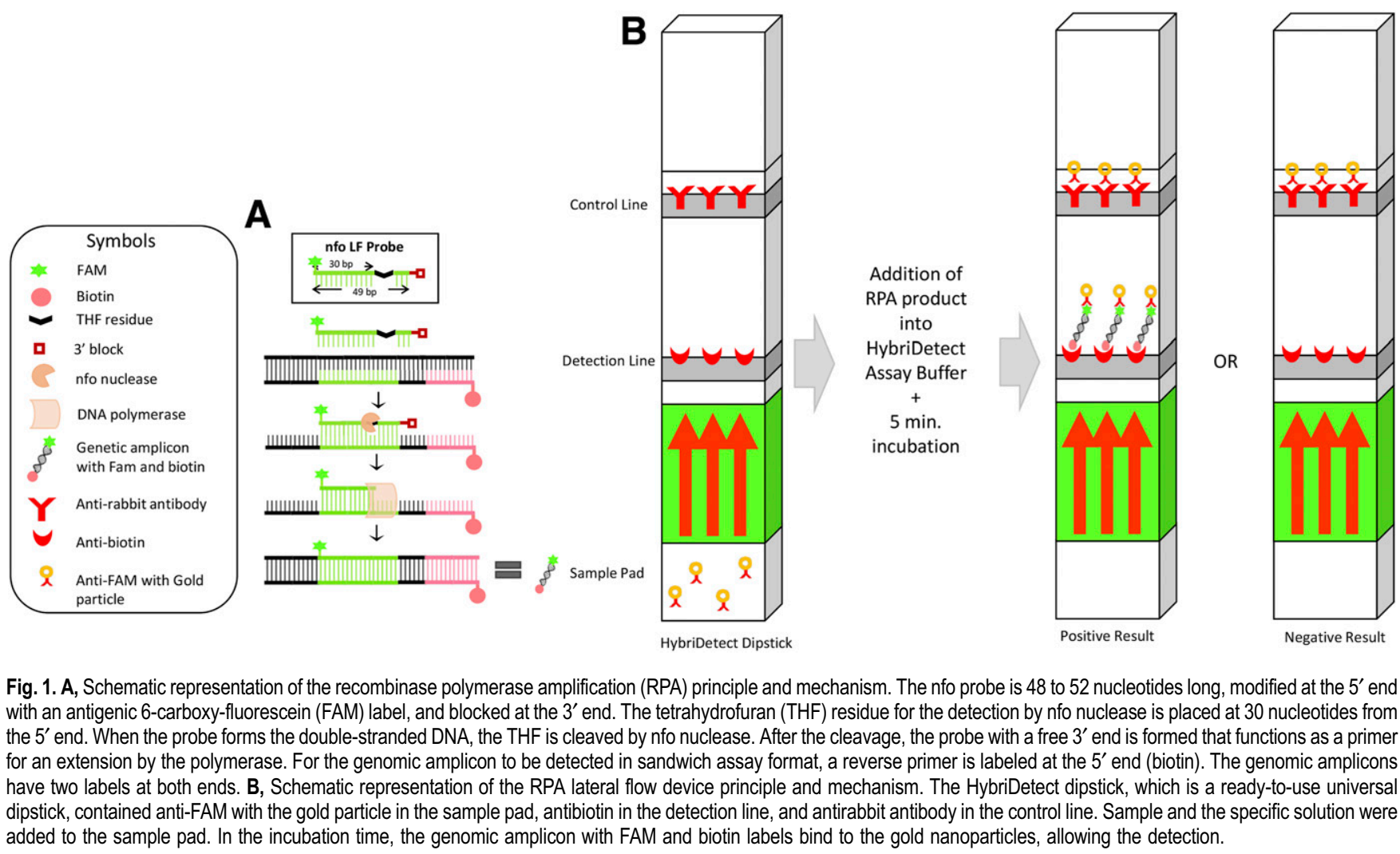




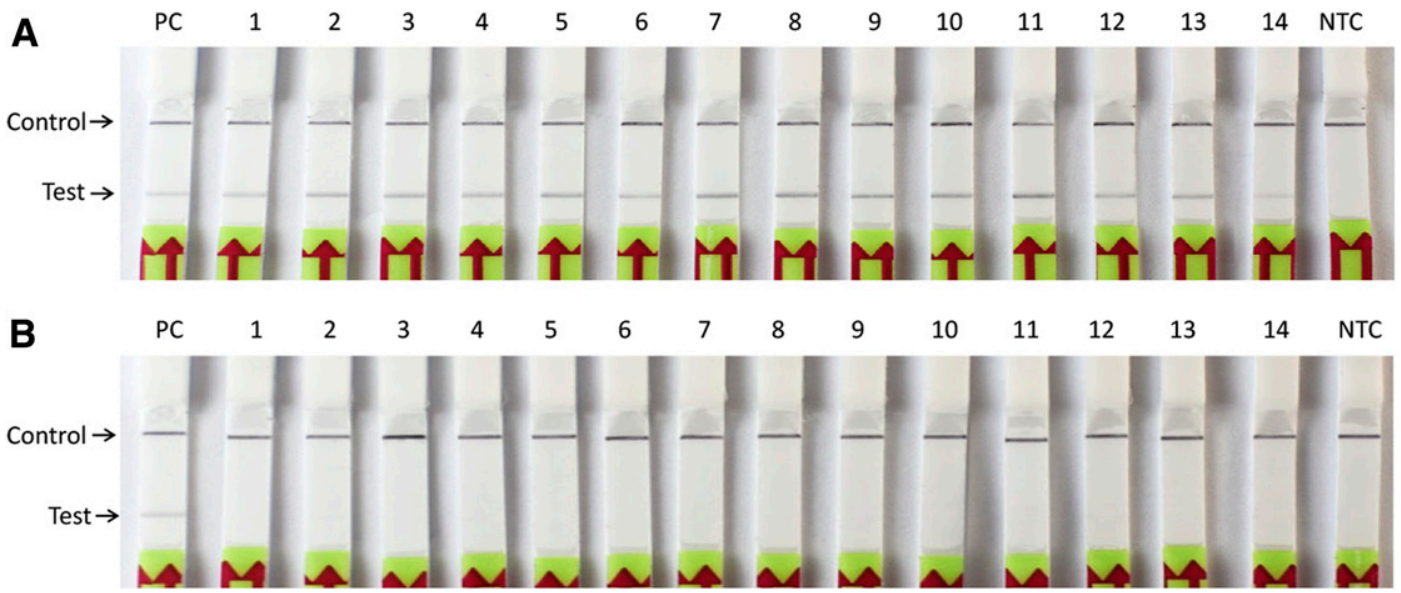

Fig. 2. Specificity validation of the recombinase polymerase amplification (RPA) for Dickeya spp. A, Inclusivity panel; 14 representative strains of Dickeya spp. Lane PC = positive control, Dickeya dianthicola (PL22), lane $1=D$. chrysanthemi (A5415), lane $2=D$. chrysanthemi (A5641), lane $3=D$. dadantii (A6066), lane $4=D$. dadantii (A6060), lane $5=D$. dianthicola (A5566), lane $6=D$. dianthicola (A5567), lane $7=D$. dianthicola (PL023), lane $8=D$. dianthicola (PL025), lane $9=D$. paradisica (A5420), lane 10 = D. paradisica (A5579), lane $11=D$. solani (A5581), lane $12=D$. solani (A5582), lane $13=D$. zeae (A5423), lane $14=D$. zeae (PL47), and lane NTC = nontemplate control (water). B, Exclusivity panel; 14 close relative representative bacterial strains. Lane PC = positive control, D. dianthicola (PL22), lane $1=$ Agrobacterium tumefaciens (A2961), lane $2=$ Enterobacter aerogenes (A3131), lane $3=$ Erwinia amylovora (A1084), lane $4=$ Erwinia sp. (A5350), lane $5=$ Klebsiella aerogenes (A3131), lane $6=$ Pectobacterium atrosepticum (A6163), lane $7=P$. carotovorum subsp. brasiliensis (A6149), lane $8=P$. carotovorum subsp. carotovorum (A5368), lane $9=P$. carotovorum subsp. odoriferum (A2686), lane 10 $=P$. wasabiae (A1852), lane $11=$ Pantoea agglomerans (A5513), lane $12=P$. ananatis (A6222), lane $13=$ Ralstonia solanacearum (A3450), lane $14=$ Xanthomonas euvesicatoria (A1701), and lane NTC = nontemplate control (water).

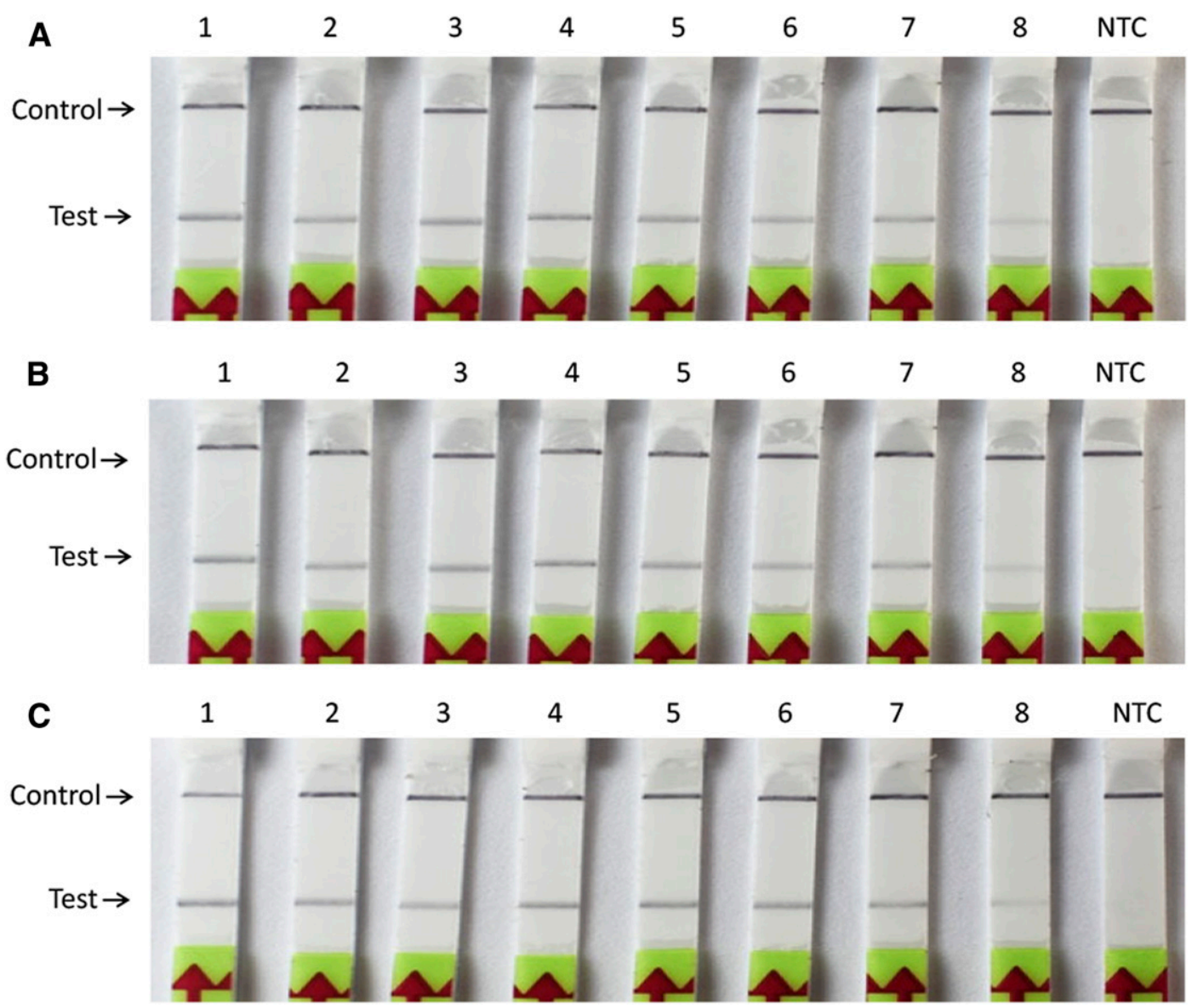

Fig. 3. Determination of detection limit of Dickeya spp.-specific recombinase polymerase amplification (RPA) assay. A, Sensitivity assay performed with 10 -fold serially diluted genomic DNA of Dickeya dianthicola (A5418). Lane $1=10 \mathrm{ng}$, lane $2=1 \mathrm{ng}$, lane $3=100 \mathrm{pg}$, lane $4=10 \mathrm{pg}$, lane $5=1 \mathrm{pg}$, lane $6=100 \mathrm{fg}, \operatorname{lane} 7=10 \mathrm{fg}$, lane $8=1$ $\mathrm{fg}$, and lane NTC = nontemplate control (water). B, Spiked assay; host stem sap was added to RPA reaction containing 10-fold serially diluted D. dianthicola genomic DNA. Lane $1=10 \mathrm{ng}$, lane $2=1 \mathrm{ng}$, lane $3=100 \mathrm{pg}$, lane $4=10 \mathrm{pg}$, lane $5=1 \mathrm{pg}$, lane $6=100 \mathrm{fg}$, lane $7=10 \mathrm{fg}$, lane $8=1 \mathrm{fg}$, and lane NTC= nontemplate control (water). C, Spiked assay; host potato tuber sap was added to RPA reaction containing 10-fold serially diluted $D$. dianthicola genomic DNA. Lane $1=10 \mathrm{ng}$, lane $2=1 \mathrm{ng}$, lane $3=$ $100 \mathrm{pg}$, lane $4=10 \mathrm{pg}$, lane $5=1 \mathrm{pg}$, lane $6=100 \mathrm{fg}$, lane $7=10 \mathrm{fg}$, lane $8=1 \mathrm{fg}$, and lane NTC = nontemplate control (water). 
developed RPA assay is accurate and highly specific for the detection of Dickeya spp.

Determination of detection limit. A 10-fold serial dilution of $D$. dianthicola (A5418) genomic DNA from $1 \mathrm{ng}$ to $1 \mathrm{fg}$ was used to evaluate the detection limit. In addition, two spiked assays were performed by adding $1 \mu \mathrm{l}$ of healthy potato leaf or potato tuber sap to the RPA reaction containing 10-fold serially diluted genomic DNA to confirm the inhibitory effect of the host sap. The sensitivity assay with purified $D$. dianthicola genomic DNA (Fig. 3A) and the two spiked sensitivity assays (Fig. 3B and C) unanimously detected 1 fg (approximately 1 genome copy or $1 \mathrm{CFU}$ ) of $D$. dianthicola genomic DNA. The sensitivity results indicated that the developed RPA assay is highly sensitive and has no inhibitory effect of host sap.

Detection from naturally and artificially infected plant samples. The developed Dickeya-specific RPA was evaluated using naturally and artificially infected plant materials. Three experiments were performed: (i) the genomic DNA was isolated from naturally infected plant materials and used for RPA detection (Fig. 4A), (ii) sap from the infected plant material was used to perform the RPA (Fig. 4B), and (iii) the sap from artificially inoculated potato, sweet potato, and taro were used for RPA detection (Fig. 5). No differences in the results were obtained when RPA assays were performed using purified genomic DNA and infected plant tissue sap. The identity of each naturally infected plant sample was confirmed by isolating the bacteria followed by sequencing; sequencing confirmed that all plant tissues were infected with $D$. dianthicola. The Dickeya sp. was accurately detected when Dickeya-specific RPA was performed with sap of different artificially infected host tissues (potato, sweet potato, and taro); $100 \%$ accurate results were obtained (Fig. 5). All three experiments indicated that the Dickeya spp. were accurately identified regardless of DNA quality (DNA or plant sap) and sample type (different hosts). No amplification was observed with the negative controls or healthy potato.

Host target detection. An RPA assay designed to detect the potato and other solanaceous plant species was used to cross-validate the possibility of getting false negatives (Ahmed et al. 2018). The potato stem tubers were artificially inoculated with different Pectobacterium spp. Both Dickeya-specific and host-specific RPA assays were performed (Fig. 6). The host-specific RPA showed positive results with all infected samples, while all results were negative with Dickeya-specific RPA (Fig. 6). Dickeya-specific RPA only showed positive amplification with the positive control $(D$. dianthicola). The inclusion of a host-specific RPA when detecting from infected plant materials will enhance the reliability of the results.

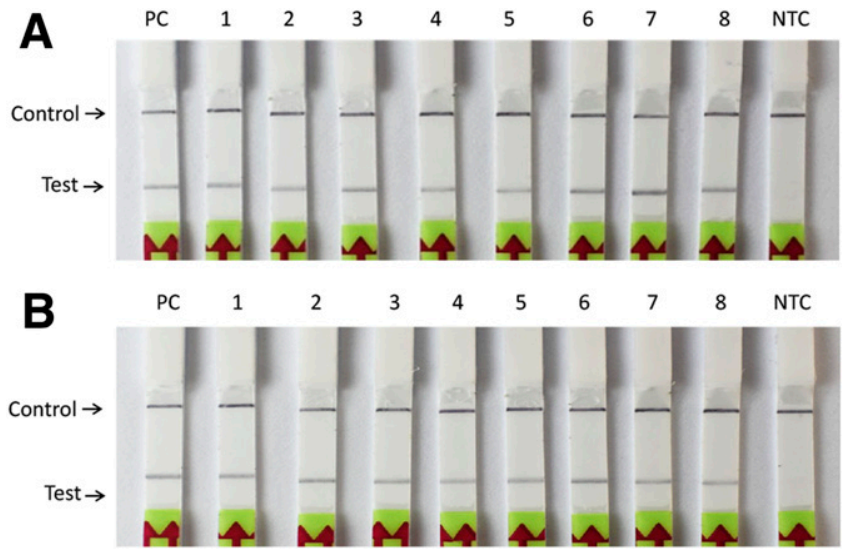

Fig. 4. Detection of Dickeya spp. from naturally infected potato plant samples using recombinase polymerase amplification assay. A, Detection of Dickeya dianthicola from purified genomic DNA. Lane $P C=$ positive control $D$. dianthicola (PL22), lane $1=\mathrm{P} 1$, lane $2=\mathrm{P} 3$, lane $3=\mathrm{P} 4$, lane $4=\mathrm{P} 7$, lane $5=\mathrm{P} 8$, lane $6=\mathrm{P} 10$, lane $7=\mathrm{P} 21$, lane $8=\mathrm{P} 22$, and lane NTC = nontemplate control (water). B, Detection of $D$. dianthicola from infected plant sap. Lane $P C=$ positive control $D$. dianthicola (PL22), lane $1=\mathrm{P} 1$, lane $2=\mathrm{P} 3$, lane $3=\mathrm{P} 4$, lane $4=\mathrm{P} 7$, lane $5=\mathrm{P} 8$, lane $6=$ $\mathrm{P} 10$, lane $7=\mathrm{P} 21$, lane $8=\mathrm{P} 22$, and lane NTC = nontemplate control (water).

\section{Discussion}

Soft rot diseases have a significant economic impact on many crops, including potato, pineapple, corn, banana, and ornamentals. Detection and differentiation of pathogens such as Dickeya and Pectobacterium spp. that cause soft rot is challenging due to genetic heterogeneity and production of nearly identical symptoms. We have developed a sensitive, rapid, and specific RPA assay to specifically detect Dickeya spp. The developed rapid assay was effectively demonstrated in-field, which is imperative for time-sensitive commodities. Additionally, this assay unanimously distinguishes the strains from the genera Dickeya and Pectobacterium.

Molecular methods such as multiplex PCR (Diallo et al. 2009) and real-time qPCR (Dobhal et al. 2020; Laurila et al. 2009; van der Wolf et al. 2013) are available for the detection of Dickeya spp. However, these tools are relatively time consuming and currently have limited applications in quarantine and confirmatory diagnostics. A LAMP assay was also developed using $m g l C$ gene by Yasuhara-Bell et al. (2017); however, the LAMP assay has a few limitations, including a higher temperature requirement $\left(65^{\circ} \mathrm{C}\right)$ and the design of the complex primers. Moreover, the reported LAMP assay showed a detection limit of only $5 \mathrm{pg}$ compared with the RPA sensitivity of $1 \mathrm{fg}$ (approximately 1 genome copy). Additionally, Dickeya-specific LAMP required a qPCR or other device to quantify the fluorescence, which limited its adaptation in unequipped or low-budget labs. In both this and a previous study (Ahmed et al. 2018), RPA showed no adverse effect of plant inhibitors on detection sensitivity; this represents a major advance over the other molecular methods, including a field-deployable LAMP assay. Compared with LAMP and other molecular methods, RPA is more sensitive, tolerant toward inhibitors, and easier to visualize, and the tubes can be incubated in the palm of one's hand (Ahmed et al. 2018; Arif et al. 2016). The RPA does not require expensive instruments. In previous studies using LAMP for detection of $X$. euvesicatoria (Larrea-Sarmiento et al. 2018), the inclusion of host DNA reduced assay sensitivity but RPA was not adversely affected by adding the host sap.

Based on in silico analyses, it was predicted that the primers and probe would detect all species within the genus Dickeya. The

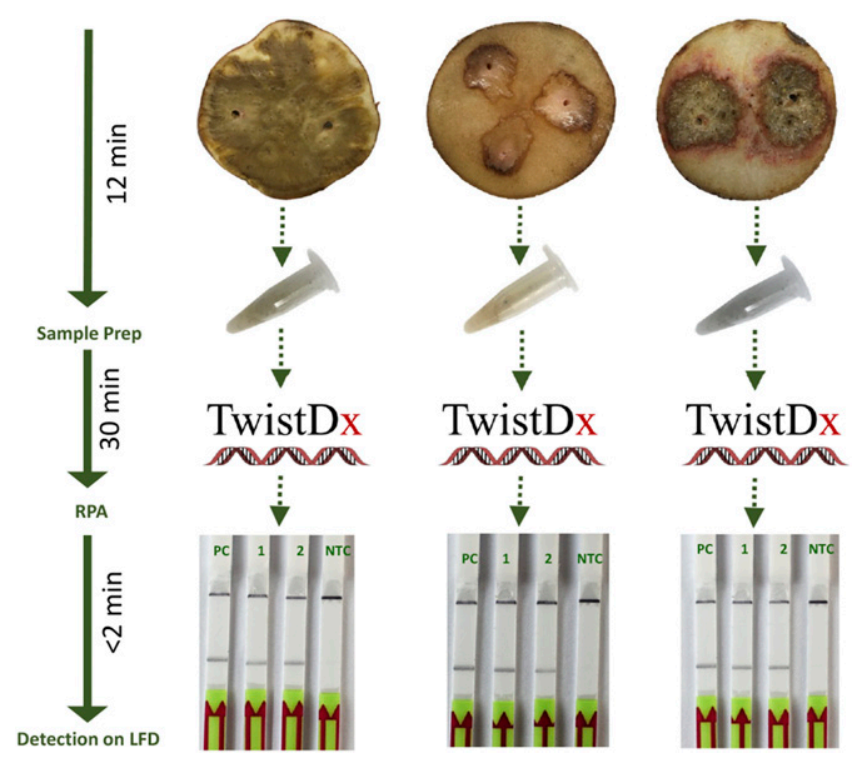

Fig. 5. Detection of Dickeya spp. from infected potato, sweet potato, and taro samples Left lane PC = positive control/Dickeya dianthicola (PL22), lane 1=D. zeae (A6056), lane $2=D$. solani (A5581), and lane NTC = nontemplate control (water). Middle lane $\mathrm{PC}=$ positive control/ $D$. dianthicola $(\mathrm{PL} 22)$, lane $1=D$. zeae $(\mathrm{A6056})$, lane $2=D$. solani (A5581), and lane NTC = nontemplate control (water). Right lane PC = positive control/D. dianthicola (PL22), lane $1=D$. zeae (A6056), lane $2=D$. solani (A5581), and lane NTC = nontemplate control (water). 
A

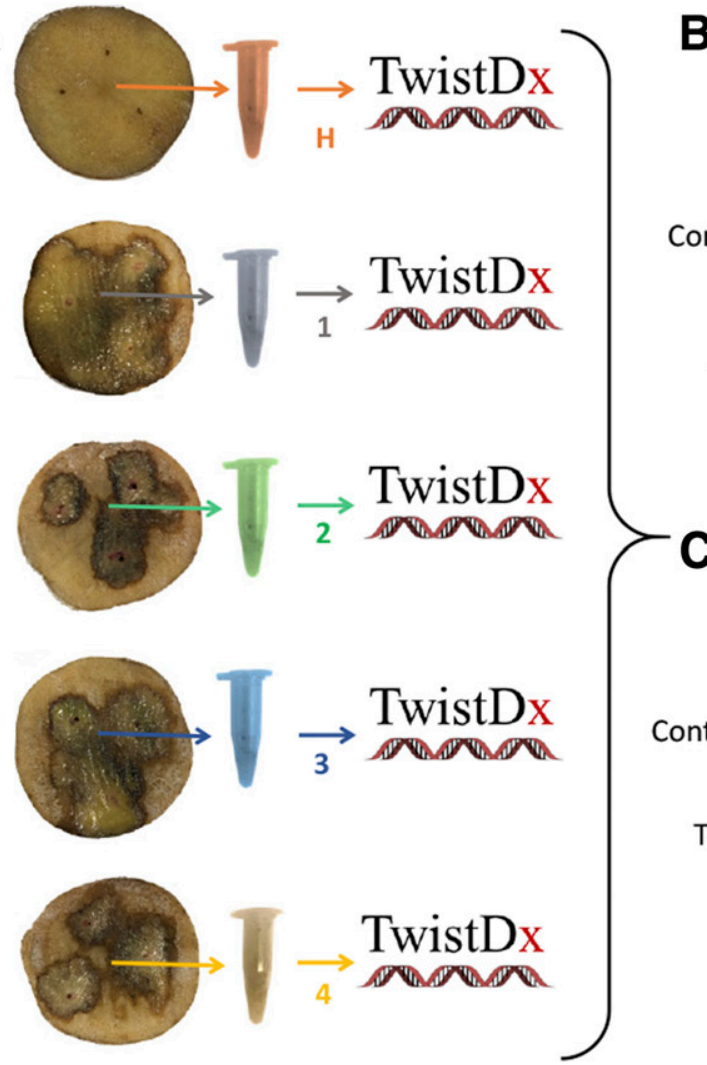

B

\section{Dickeya-specific RPA}

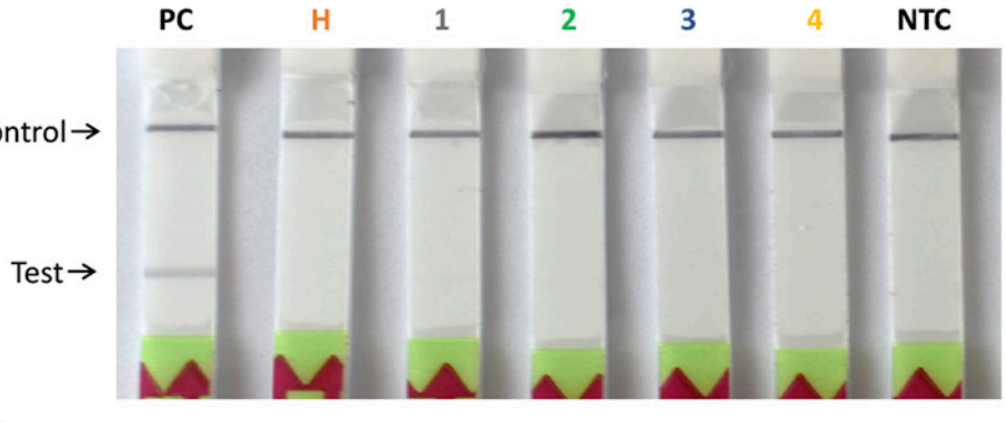

H

1

2

3

4 NTC

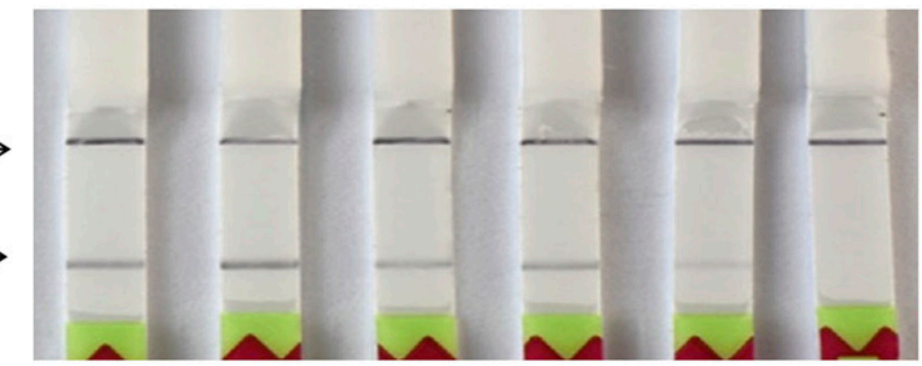

Host-specific RPA

Fig. 6. Host-specific recombinase polymerase amplification (RPA) to validate the developed Dickeya-specific RPA. A, Infected potato slices with different Pectobacterium spp. B, Detection using Dickeya-specific recombinase polymerase amplification (RPA). Lane $P C=$ positive control/Dickeya dianthicola $(\mathrm{PLO22})$, lane $\mathrm{H}=$ healthy potato, lane $1=$ Pectobacterium wasabiae (A1852), lane $2=P$. carotovorum subsp. odoriferum (A2686), lane $3=P$. carotovorum subsp. carotovorum (A5278), lane $4=P$. carotovorum subsp. brasiliensis (A6149), and lane NTC = nontemplate control (water). C, Detection of host target using host-specific RPA assay. Lane $\mathrm{H}=$ healthy potato, lane $1=P$. wasabiae (A1852), lane $2=P$. carotovorum subsp. odoriferum (A2686), lane $3=P$. carotovorum subsp. carotovorum (A5278), lane $4=P$. carotovorum subsp. brasiliensis (A6149), and lane NTC = nontemplate control (water). No false negatives or false positives were observed.

analysis showed $100 \%$ identity only with Dickeya strains, which was expected because the selected genome region was unique to Dickeya spp. It has already been proven that a unique target genome sequence is peremptory for the development of a robust and highly specific assay (Dobhal et al. 2020; Larrea-Sarmiento et al. 2018; Ouyang et al. 2013). The specificity validation using the strains included in inclusivity and exclusivity panels indicated that the developed RPA is highly specific and only detects the strains from Dickeya spp.; no amplification or cross-reactivity was observed when tested against Pectobacterium, a closely related genus. No discrepancy was observed when RPA was validated using the naturally and artificially infected plant samples (Figs. 4 and 5). When different hosts (potato, taro, and sweet potato) were artificially inoculated with Dickeya strains and sap exuding after the infection was used to perform the Dickeya-specific RPA assay, all infected samples were detected with $100 \%$ accuracy. The procedure can be completed within 45 mins from sample preparation to final detection on LFD (Fig. 5), and this is remarkably rapid compared with the qPCR and LAMP assays (Dobhal et al. 2019; Ocenar et al. 2019; Ouyang et al. 2013).

The coupling of an LFD with RPA facilitates the application of this technique for on-site detection. LFD and lyophilized RPA reagents do not require refrigeration for transport. Inclusion of an RPA assay targeting the host ITS region enhanced the reliability of the results-it eliminated the uncertainty of obtaining false negatives, which is a critical aspect of a reliable diagnostic assay (Fig. 6).

In summary, we used a unique target genome region within Dickeya spp. to design a highly specific, robust, and rapid RPA assay for on-site detection of devastating soft rot and blackleg pathogens in Dickeya spp. The developed assay is user friendly, does not require DNA isolation, and has no effect of plant inhibitors. The assay has applications in routine diagnostics, epidemiological studies, disease management, and biosecurity.

\section{Literature Cited}

Ahmed, F. A., Larrea-Sarmiento, A., Alvarez, A. M., and Arif, M. 2018. Genomeinformed diagnostics for specific and rapid detection of Pectobacterium species using recombinase polymerase amplification coupled with a lateral flow device. Sci. Rep. 8:15972.

Arif, M., Busot, G. Y., Mann, R., Rodoni, B., and Stack, J. P. 2016. Detection of the select agent Rathayibacter toxicus using recombinase polymerase amplification coupled with a lateral flow device. (Abstr.) Phytopathology 106:S4.23.

Avrova, A. O., Hyman, L. J., Toth, R. L., and Toth, I. K. 2002. Application of amplified fragment length polymorphism fingerprinting for taxonomy and identification of the soft rot bacteria Erwinia carotovora and Erwinia chrysanthemi. Appl. Environ. Microbiol. 68:1499-1508.

Boluk, G., and Arif, M. 2019. First report of Dickeya dianthicola as a causal agent of bacterial soft rot of potato in Hawaii. Plant Dis. 103:2943.

Brady, C. L., Cleenwerck, I., Denman, S., Venter, S. N., Rodriguez-Palenzuela, P. Coutinho, T. A., and De Vos, P. 2012. Proposal to reclassify Brenneria quercina (Hildebrand and Schroth 1967) Hauben et al. 1999 into a new genus, Lonsdalea gen. nov., as Lonsdalea quercina comb. nov., descriptions of Lonsdalea quercina subsp. quercina comb. nov., Lonsdalea quercina subsp. iberica subsp. nov. and Lonsdalea quercina subsp. britannica subsp. nov., emendation of the description of the genus Brenneria, reclassification of Dickeya dieffenbachiae as Dickeya dadantii subsp. dieffenbachiae comb. nov., and emendation of the description of Dickeya dadantii. Int. J. Syst. Evol. Microbiol. 62:1592-1602.

Czajkowski, R., Perombelon, M., Jafra, S., Lojkowska, E., Potrykus, M., van der Wolf, J., and Sledz, W. 2015. Detection, identification and differentiation of Pectobacterium and Dickeya species causing potato blackleg and tuber soft rot: A review. Ann. Appl. Biol. 166:18-38.

Diallo, S., Latour, X., Groboillot, A., Smadja, B., Copin, P., Orange, N., Feuilloley, M. G. J., and Chevalier, S. 2009. Simultaneous and selective detection of two major soft rot pathogens of potato: Pectobacterium atrosepticum (Erwinia carotovora subsp. atrosepticum) and Dickeya spp. (Erwinia chrysanthemi). Eur. J. Plant Pathol. 125:349-354. 
Dobhal, S., Boluk, G., Babler, B., Stulberg, M., Rascoe, J., Nakhla, M. K., Chapman, T., Crockford, A., Melzer, M. J., Alvarez, A. M., and Arif, M. 2020. Comparative genomics reveals signature regions used to develop a robust and sensitive multiplex TaqMan real-time qPCR assay to detect the genus Dickeya and Dickeya dianthicola. J. Appl. Microbiol. doi:10.1111/ jam. 14579

Dobhal, S., Larrea-Sarmiento, A., Alvarez, A. M., and Arif, M. 2019. Development of a loop-mediated isothermal amplification assay for specific detection of all known subspecies of Clavibacter michiganensis. J. Appl. Microbiol. 126:388-401.

Fujimoto, T., Yasuoka, S., Aono, Y., Nakayama, T., Ohki, T., Sayama, M., and Maoka, T. 2018. Biochemical, physiological, and molecular characterization of Dickeya dianthicola (formerly named Erwinia chrysanthemi) causing potato blackleg disease in Japan. J. Gen. Plant Pathol. 84:124-136.

Gardan, L., Gouy, C., Christen, R., and Samson, R. 2003. Elevation of three subspecies of Pectobacterium carotovorum to species level: Pectobacterium atrosepticum sp. nov., Pectobacterium betavasculorum sp. nov. and Pectobacterium wasabiae sp. nov. Int. J. Syst. Evol. Microbiol. 53:381-391.

Golanowska, M., Kielar, J., and Lojkowska, E. 2016. The effect of temperature on the phenotypic features and the maceration ability of Dickeya solani strains isolated in Finland, Israel and Poland. Eur. J. Plant Pathol. 147:803-817.

Hommais, F., Zghidi-Abouzid, O., Oger-Desfeux, C., Pineau-Chapelle, E., Van Gijsegem, F., Nasser, W., and Reverchon, S. 2011. lpxC and yafS are the most suitable internal controls to normalize real time RT-qPCR expression in the phytopathogenic bacteria Dickeya dadantii. PLoS One 6:e20269.

Humphris, S. N., Cahill, G., Elphinstone, J. G., Kelly, R., Parkinson, N. M., Pritchard, L., Toth, I. K., and Saddler, G. S. 2015. Detection of the bacterial potato pathogens Pectobacterium and Dickeya spp. using conventional and Real-Time PCR. Methods Mol. Biol. 1302:1-16.

Joutsjoki, T., Laurila, J., Pirhonen, M., Lehtinen, A., and Hannukkala, A. 2005. Diagnostics and incidence of black leg caused by Erwinia bacteria in Finland. Pages 717-718 in: Proc. 16th Triennial Conf. EAPR, Bilbao, Spain.

Kaneshiro, W. K., Burger, M., Vine, B., de Silva, A., and Alvarez, A. M. 2008. Characterization of Erwinia chrysanthemi from a bacterial heart rot of pineapple outbreak in Hawaii. Plant Dis. 92:1444-1450.

Kumar, A., Hunjan, M. S., Kaur, H., Rawal, R., Kumar, A., and Singh, P. P. 2017. A review on bacterial stalk rot disease of maize caused by Dickeya zeae. J. Appl. Nat. Sci. 9:1214-1225.

Larrea-Sarmiento, A., Dhakal, U., Boluk, G., Fatdal, L., Alvarez, A., StrayerScherer, A., Paret, M., Jones, J., Jenkins, D., and Arif, M. 2018. Development of a genome-informed loop-mediated isothermal amplification assay for rapid and specific detection of Xanthomonas euvesicatoria. Sci. Rep. 8:14298.

Laurila, J., Hannukkala, A., Nykyri, J., Pasanen, M., Hélias, V., Garlant, L., and Pirhonen, M. 2009. Symptoms and yield reduction caused by Dickeya spp. strains isolated from potato and river water in Finland. Eur. J. Plant Pathol. 126:249-262.

Ma, B., Hibbing, M. E., Kim, H. S., Reedy, R. M., Yedidia, I., Breuer, J., Breuer, J., Glasner, J. D., Perna, N. T., Kelman, A., and Charkowski, A. O. 2007. Host range and molecular phylogenies of the soft rot enterobacterial genera Pectobacterium and Dickeya. Phytopathology 97:1150-1163.

Marrero, G., Schneider, K. L., Jenkins, D. M., and Alvarez, A. M. 2013. Phylogeny and classification of Dickeya based on multilocus sequence analysis. Int. J. Syst. Evol. Microbiol. 63:3524-3539.

Nassar, A., Darrasse, A., Lemattre, M., Kotoujansky, A., Dervin, C., Vedel, R., and Bertheau, Y. 1996. Characterization of Erwinia chrysanthemi by pectinolytic isozyme polymorphism and restriction fragment length polymorphism analysis of PCR-amplified fragments of pel genes. Appl. Environ. Microbiol. 62:2228-2235

Ngadze, E., Coutinho, T. A., and van der Waals, J. E. 2010. First report of soft rot of potatoes caused by Dickeya dadantii in Zimbabwe. Plant Dis. 94:1263.

Notomi, T., Okayama, H., Masubuchi, H., Yonekawa, T., Watanabe, K., Amino, N., and Hase, T. 2000. Loop-mediated isothermal amplification of DNA. Nucleic Acids Res. 28:E63.

Ocenar, J., Arizala, D., Boluk, G., Dhakal, U., Gunarathne, S., Paudel, S., Dobhal, S., and Arif, M. 2019. Development of a robust, field-deployable loop-mediated isothermal amplification (LAMP) assay for specific detection of potato pathogen Dickeya dianthicola targeting a unique genomic region. PLoS One 14:e 0218868

Ouyang, P., Arif, M., Fletcher, J., Melcher, U., and Ochoa Corona, F. M. 2013. Enhanced reliability and accuracy for field deployable bioforensic detection and discrimination of Xylella fastidiosa subsp. pauca, causal agent of citrus variegated chlorosis using razor ex technology and TaqMan quantitative PCR. PLoS One 8:e81647.

Palacio-Bielsa, A., Cambra, M. A., and Lopez, M. M. 2006. Characterisation of potato isolates of Dickeya chrysanthemi in Spain by a microtitre system for biovar determination. Ann. Appl. Biol. 148:157-164.

Parkinson, N., DeVos, P., Pirhonen, M., and Elphinstone, J. 2014. Dickeya aquatica sp. nov., isolated from waterways. Int. J. Syst. Evol. Microbiol. 64: 2264-2266

Pérombelon, M. C. M. 2002. Potato diseases caused by soft rot erwinias: An overview of pathogenesis. Plant Pathol. 51:1-12.

Piepenburg, O., Williams, C. H., Stemple, D. L., and Armes, N. A. 2006. DNA detection using recombination proteins. PLoS Biol. 4:e204

Pritchard, L., Glover, R. H., Humphris, S., Elphinstone, J. G., and Toth, I. K. 2016 Genomics and taxonomy in diagnostics for food security: Soft-rotting enterobacterial plant pathogens. Anal. Methods 8:12-24.

Pritchard, L., Humphris, S., Saddler, G. S., Parkinson, N. M., Bertrand, V., Elphinstone, J. G., and Toth, I. K. 2013. Detection of phytopathogens of the genus Dickeya using a PCR primer prediction pipeline for draft bacterial genome sequences. Plant Pathol. 62:587-596.

Samson, R., Legendre, J. B., Christen, R., Fischer-Le Saux, M., Achouak, W., and Gardan, L. 2005. Transfer of Pectobacterium chrysanthemi (Burkholder et al. 1953) Brenner et al. 1973 and Brenneria paradisiaca to the genus Dickeya gen. nov. as Dickeya chrysanthemi comb. nov. and Dickeya paradisiaca comb. nov. and delineation of four novel species, Dickeya dadantii sp. nov., Dickeya dianthicola sp. nov., Dickeya dieffenbachiae sp. nov. and Dickeya zeae sp. nov. Int. J. Syst. Evol. Microbiol. 55:1415-1427.

Singh, U., Trevors, C. M., De Boer, S. H., and Janse, J. D. 2000. Fimbrialspecific monoclonal antibody-based ELISA for European potato strains of Erwinia chrysanthemi and comparison to PCR. Plant Dis. 84:443448.

Sławiak, M., van Beckhoven, J. R. C. M., Speksnijder, A. G. C. L., Czajkowski, R., Grabe, G., and van der Wolf, J. M. 2009. Biochemical and genetical analysis reveal a new clade of biovar 3 Dickeya spp. strains isolated from potato in Europe. Eur. J. Plant Pathol. 125:245-261.

Sueno, W. S. K., Marrero, G., de Silva, A. S., Sether, D., and Alvarez, A. M. 2014 Diversity of Dickeya sp. strains collected from pineapple plants and irrigation water in Hawaii. Plant Dis. 98:817-824.

Tian, Y., Zhao, Y., Yuan, X., Yi, J., Fan, J., Xu, Z., Hu, B., De Boer, S. H., and Li, X. 2016. Dickeya fangzhongdai sp. nov., a plant-pathogenic bacterium isolated from pear trees (Pyrus pyrifolia). Int. J. Syst. Evol. Microbiol. 66: 2831-2835.

Tsror, L., Erlich, O., Lebiush, S., Hazanovsky, M., Zig, U., Slawiak, M., Grabe, G., van der Wolf, J. M., and van de Haar, J. J. 2008. Assessment of recent outbreaks of Dickeya sp. (syn. Erwinia chrysanthemi) slow wilt in potato crops in Israel. Eur. J. Plant Pathol. 123:311-320.

van der Wolf, J. M., de Haas, B. H., van Hoof, R., de Haan, E. G., and van den Bovenkamp, G. W. 2013. Development and evaluation of Taqman assays for the differentiation of Dickeya (sub)species. Int. J. Syst. Evol. Microbiol. 138: 695-709.

van der Wolf, J. M., Nijhuis, E. H., Kowalewska, M. J., Saddler, G. S., Parkinson, N., Elphinstone, J. G., Pritchard, L., Toth, I. K., Lojkowska, E., Potrykus, M. Waleron, M., de Vos, P., Cleenwerck, I., Pirhonen, M., Garlant, L., Helias, V., Pothier, J. F., Pfluger, V., Duffy, B., Tsror, L., and Manulis, S. 2014. Dickeya solani sp. nov., a pectinolytic plant-pathogenic bacterium isolated from potato (Solanum tuberosum). Int. J. Syst. Evol. Microbiol. 64:768-774.

Waleron, M., Waleron, K., Podhajska, A. J., and Lojkowska, E. 2002. Genotyping of bacteria belonging to the former Erwinia genus by PCR-RFLP analysis of a recA gene fragment. Microbiology 148:583-595.

Yasuhara-Bell, J., Marrero, G., Arif, M., de Silva, A., and Alvarez, M. A. 2017 Development of a loop-mediated isothermal amplification assay for the detection of Dickeya spp. Phytopathology 107:1339-1345. 